\title{
Clinico-histomorphological spectrum of abnormal uterine bleeding
}

\author{
Ramesh B.H ${ }^{1, *}$, Rajeshwari . $\mathbf{K}^{2}$ \\ ${ }^{1}$ Professor and HOD, Dept. of Pathology, Raichur Institute of Medical Sciences, Raichur, Karnataka, ${ }^{\mathbf{2}}$ Assistant Professor, Dept. \\ of Pathology, Gulbarga Institute of Medical Sciences, Karnataka, India
}

*Corresponding Author:

Email: rameshpath@ rediffmail.com

Received: $7^{\text {th }}$ June, 2017

Accepted: $1^{\text {st }}$ March, 2018

\begin{abstract}
Introduction: Abnormal uterine bleeding is considered as one of the most common and perplexing problems both to the patient and gynecologist. Histopathological diagnosis of organic cause of menorrhagia plays an important for appropriate and accurate therapy.

Aims and Objectives: The present study mainly aimed at correlating histopathological findings with age, parity and bleeding pattern presented by the patient and to study various associated organic lesions in abnormal uterine bleeding.

Materials and Methods: A reterospective study of 111 hysterectomies in patients with complaints of abnormal uterine bleeding over a period of one year from June 2016-May 2017. The histopathological findings with clinical data that includes age, parity, presenting symptoms and other details of the patients with abnormal uterine bleeding was collected and analyzed.

Results: In this study, majority of cases were in $4^{\text {th }} \& 5^{\text {th }}$ decade $(81.08 \%)$ and were multiparous $(93.7 \%)$. Menorrhagia was the most frequent presenting complaint (58.57\%) followed by metrorrhagia in $13.51 \%$. Of the 111 cases, $51.35 \%$ of cases showed histological features of dysfunctional uterine bleeding followed by $48.65 \%$ cases with organic lesions. Among organic lesions maximum number of cases of adenomyosis followed by leiomyoma was observed.

Conclusion: Clinico-histomorphological evaluation of abnormal uterine bleeding in our study showed maximum number of dysfunctional uterine bleeding followed by adenomyosis and leiyomyoma. Age has definite influence on endometrial histology. There is no constant relationship between the pattern of endometrium and the type of bleeding in cases of abnormal uterine bleeding.
\end{abstract}

Keywords: Abnormal uterine bleeding, Histomorphology, Egnndometrium.

\section{Introduction}

Abnormal uterine bleeding (AUB) is one of the most common clinical problems in gynaecology. ${ }^{1}$ Among the women attending gynaecological out patient department, $30-70 \%$ of the cases presents with abnormal uterine bleeding. ${ }^{2}$

Although abnormal uterine bleeding can be caused by well-defined organic pathologic conditions, such as chronic endometritis, endometrial polyp, submucosal leiomyomas, or endometrial neoplasms, the largest single group encompasses functional disturbances, referred to as dysfunctional uterine bleeding (DUB). DUB is defined as any excessive bleeding (excessively heavy, pro longed or frequent) of uterine origin which is not due to demonstrable organic disease, complications of pregnancy or systemic disease. An endometerial biopsy should be performed on all women over 35 years with or pre-malignant lesion (e.g atypical hyperplasia). ${ }^{3}$

Irregular menstrual bleeding justifies investigating women in younger age group. ${ }^{4}$ Adenocarinoma of the endometrium is often preceded by proliferative precursor lesions "endometrial hyperplasia". Thus, early accurate diagnosis and proper treatment of endometrial hyperplastic lesions are essential to prevent progress to endometrial cancer and preclude unwarranted hysterectomy without definitive diagnosis. $^{5}$
In most cases, it is associated with anovulatory or oligo-ovulatory cycles, leading to a shoot in the oestrogen levels, which are unopposed due to absence of progesterone. ${ }^{6}$ During adolescence, it may be due to a failure of the hypothalamic-pituitary system to respond to the positive feedback of oestrogen. In the perimenopausal years, the anovulatory bleeding may be due to the declining functional capacity of ovary or a careful screening for malignancy is imperative and should be treated promptly. ${ }^{7,8}$ Until the pathology underlying menorrhagia is accurately diagnosed, correct methods of treatment are impossible,

The present study mainly aimed at correlating histopathological findings with age, parity and bleeding pattern presented by the patient and to study various associated organic pathology in clinically diagnosed cases of AUB.

\section{Materials and Methods}

Present study is a retrospective type of study conducted over 111 cases over a period of one year from June 2016- June 2017 in the department of pathology at a tertiary care centre.

Following inclusion and exclusion criteria were adopted in our study -

\section{Inclusion Criteria:}

1. All the patients who were diagnosed clinically as abnormal uterine bleeding (AUB) cases. 
2. The clinical diagnosed AUB cases with only hysterectomy specimens were included in the present study.

\section{Exclusion Criteria:}

1. Inadequate and improperly preserved specimens were excluded.

2. Women with bleeding due to pregnancy like abortion, gestational trophoblastic diseases, ectopic pregnancy and clinical diagnosis of local lesions like carcinoma cervix were excluded from the study.

Hysterectomy specimens received to the department of pathology were subjected to detailed gross examination and fixed in $10 \%$ buffered neutral formalin and processed. The sections of 3-4 microns were cut and stained with haematoxylin and eosin for histopathological diagnosis. A detailed clinical history, gynaecological examination and radiological findings were recorded. The clinical and histopathological findings were analyzed and following observations were made.
Statistical Analysis: The collected data was tabulated, analyzed and subjected for statistical analysis using SPSS 17.0. Results are presented as range for quantitative data and number and percentage for qualitative data.

\section{Results}

The present study included evaluation of 111 hysterectomy specimens resected in cases of abnormal uterine bleeding received at the department of pathology, over a period of one year.

A total of 622 hysterectomy specimens were received to the department of pathology. Out of which 111 hysterectomies were performed with clinical diagnosis of AUB accounting for $17.85 \%$ of the total hysterectomy specimens received. Among 111 cases of AUB 57 cases showed histologic features of DUB without organic lesions accounting for $51.35 \%$ of the cases and 54 cases showed features associated with intrauterine organic pathology accounting for $48.65 \%$ of the cases as shown in graph 1 .

Graph 1: The distribution of cases with abnormal uterine bleeding

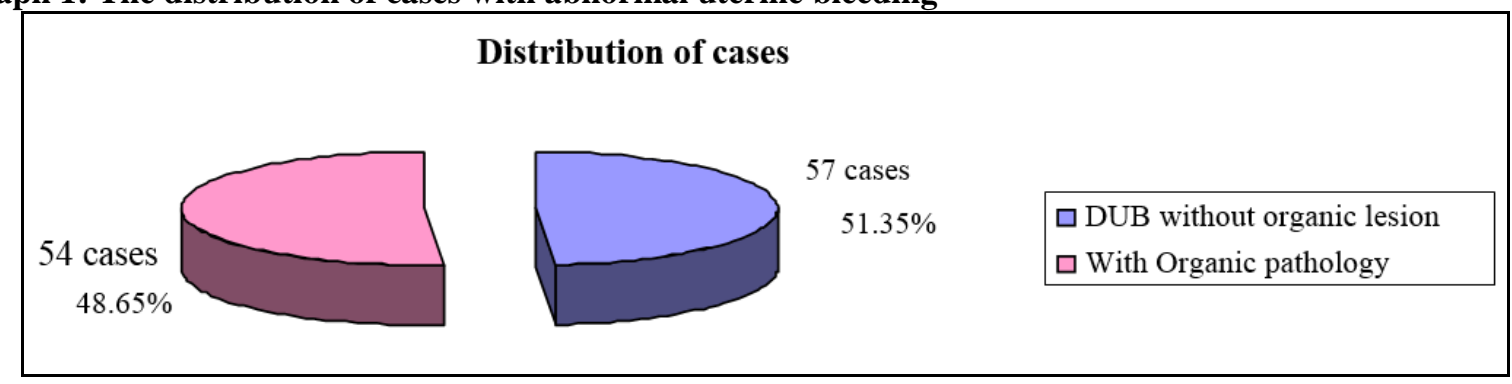

Among 111 cases of AUB, proliferative phase (Fig. 1) was the most commonest pattern of endometrium accounting for $49.54 \%$ followed by secretory phase (Fig. 2) in $15.31 \%$ of cases as shown in table 1.

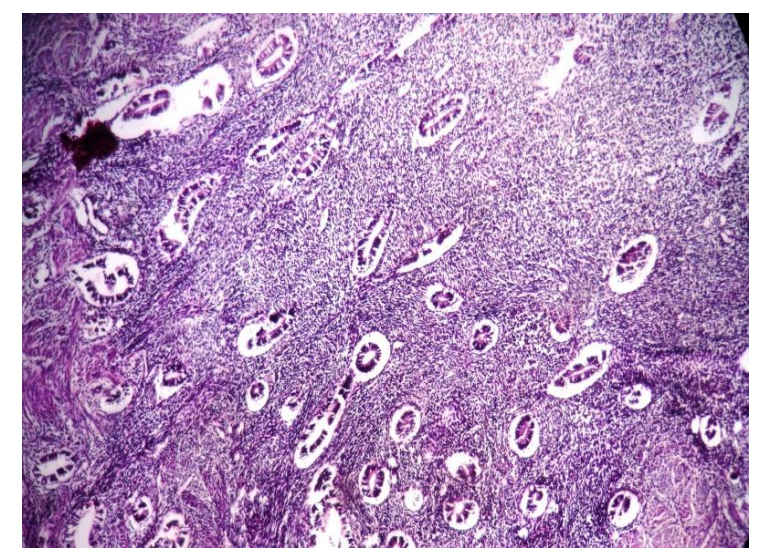

Fig. 1. Microphotograph of proliferative phase showing tubular glands with columnar cells surrounded by dense stroma with normal gland to stroma ratio

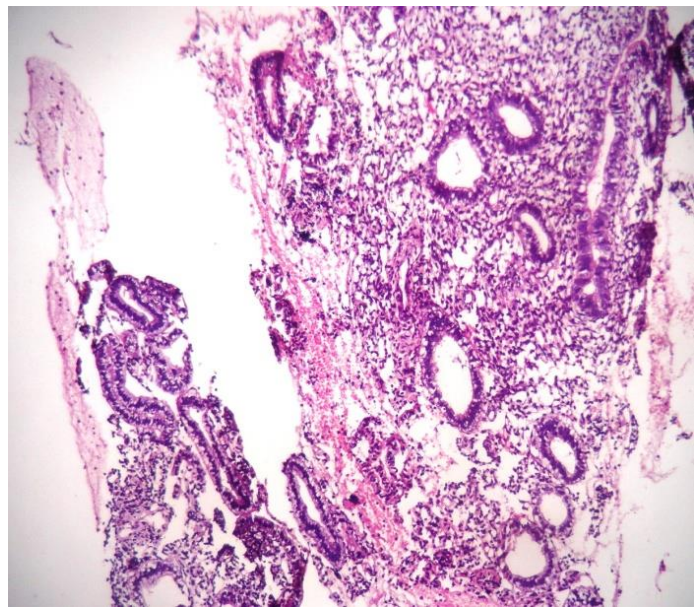

Fig. 2: Microphotograph of secretary phase showing torturous glands with sub nuclear vacuoles surrounded by edematous stroma 
Table 1: The distribution of histologic patterns of endometrium

\begin{tabular}{|c|c|c|c|}
\hline S. No. & Type of Endometrium & No. of cases & Percentage (\%) \\
\hline 1 & Proliferative Phase & 55 & 49.54 \\
\hline 2 & Secretory Phase & 17 & 15.31 \\
\hline 3 & Atrophic endometrium & 04 & 3.60 \\
\hline 4 & Simple endometrial hyperplasia & 17 & 15.31 \\
\hline 5 & Complex hyperplasia & 08 & 7.20 \\
\hline 6 & Complex hyperplasia with atypia & 01 & 0.90 \\
\hline 7 & Endometrial polyp & 05 & 4.50 \\
\hline 8 & Decidual reaction & 04 & 3.60 \\
\hline \multicolumn{2}{|c|}{ Total } & 111 & $100 \%$ \\
\hline
\end{tabular}

In the present study, majority of the patients in AUB belonged to the age group of 31-40 years accounting for $42.34 \%$ of the cases followed by 41 50 years in $38.74 \%$ of the cases as shown in table 2 .

Table 2: The age distribution in abnormal uterine bleeding cases

\begin{tabular}{|l|c|c|}
\hline S. No. & Age (in yrs) & Total cases \\
\hline 1 & $21-30$ & $11(09.91)$ \\
\hline 2 & $31-40$ & $47(42.34)$ \\
\hline 3 & $41-50$ & $43(38.74)$ \\
\hline 4 & $51-60$ & $09(08.11)$ \\
\hline 5 & $61-70$ & $01(0.90)$ \\
\hline Total & & $111(100 \%)$ \\
\hline
\end{tabular}

Our study observed that AUB was commonly seen in multiparous accounting for $93.3 \%$ of the cases. In the present study, menorrhagia was the commonest type of bleeding in AUB cases accounting for $58.57 \%$ of the cases followed by metrorrhagia in $13.51 \%$ of the cases. Post menopausal bleeding and menometrorrhagia was present in each $7.21 \%$ of cases. Profuse bleeding following amenorrhoea was observed in $2.70 \%$ of cases as shown in table 3 .

Table 3: The salient clinical features in abnormal uterine bleeding

\begin{tabular}{|l|c|c|c|c|c|}
\hline S. No. & Symptoms & $\begin{array}{c}\text { Without organic } \\
\text { lesions (\%) }\end{array}$ & $\begin{array}{c}\text { With organic } \\
\text { Pathology (\%) }\end{array}$ & Total & $\%$ \\
\hline 1 & Menorrhagia & $32(56.14)$ & $33(61.11)$ & 65 & 58.57 \\
\hline 2 & Metrorrhagia & $8(14.04)$ & $7(12.96)$ & 15 & 13.51 \\
\hline 3 & $\begin{array}{c}\text { Postmenopausal } \\
\text { bleeding }\end{array}$ & $5(08.77)$ & $3(05.55)$ & 08 & 7.21 \\
\hline 4 & Meno metrorrhagia & $4(07.01)$ & $4(07.40)$ & 08 & 7.21 \\
\hline 5 & Polymenorrhagia & $4(07.01)$ & $3(05.55)$ & 07 & 6.30 \\
\hline 6 & Continuous bleeding & $1(01.75)$ & $3(05.55)$ & 04 & 3.60 \\
\hline 7 & $\begin{array}{c}\text { Amenorrhoea followed } \\
\text { by bleeding }\end{array}$ & $2(03.50)$ & $1(01.85)$ & 03 & 2.70 \\
\hline 8 & Dysmenorrhoea & $1(01.75)$ & $0(0.0)$ & 01 & 0.90 \\
\hline & Total & 57 & 54 & 111 & 100 \\
\hline
\end{tabular}

In patients with proliferative phase, menorrhagia was the commonest $(65.45 \%)$ type of bleeding followed by metrorrhagia in $9(16.36 \%)$ and menometrorrhagia in 3 cases $(5.45 \%)$. Post menopausal bleeding, polymenorrhoea and ammenorrhoea followed by bleeding was found in 2 cases each (10.90\%). Continous bleeding was found in one $(1.81 \%)$ case. Endometrial polyp observed in two cases, one presented with menorrhagia and other with menometrorrhagia.

Among 28 cases of endometrial hyperplasia, menorrhagia was present in 16 cases $(57.14 \%)$ followed by menometrorrhagia in $4(14.28 \%)$ cases. Metrorrhagia and polymenorrhoea was found in 2 cases each (15.28\%). Post menopausal bleeding and amenorrhoea followed by bleeding in one case each (7.14). Two cases of endometrial polyp observed, one presented with polymenorrhoea and other with menorrhagia.

In secretory endometrium, menorrhagia was common type of bleeding in 8 cases $(53.33 \%)$ followed by metrorrhagia (17.64\%). Post menopausal bleeding and polymenorrhoea found in two case each (23.53\%). Menometrorrhagia and dysmenorrhoea were found in one case each (11.76\%). Endometrial polyp observed in two cases, one presented with menorrhagia and other with post menopausal bleeding.

In atrophic type of endometrium, post menopausal bleeding was commonest found in 3 cases $(50 \%)$ 
followed by continuous bleeding in two cases (33.33\%) and menorrhagia in one case $(16.66 \%)$. Products of conception presented with continuous bleeding in one case. Decidual reaction (Pill endometrium) was observed in 3 cases.

The duration of symptoms ranged from a minimum of four days to a maximum of seven years. Most frequent duration of period involved was 1 year $(22$ cases). 24 patients proven to have DUB sought radical treatment after a minimum period of 1 year. On the other hand, a greater proportion of patients $(80 \%)$ with associated intrauterine pathology underwent hysterectomy earlier, within a period of one year.

Proliferative phase was the dominant type of endometrium in age group from 21-50 years, accounting for $50.88 \%$ of the DUB cases. Secretory endometrium constituted $15.79 \%$ was seen maximum in the age group of 31-40 years. Simple endometrial hyperplasia (Fig. 3) constituted $17.54 \%$ occurred maximally between the age group of 41-50 years. Complex hyperplasia constituted $10.53 \%$ of cases occurred maximally between the age group of 31-50 years. Complex hyperplasia with atypia involved in one patient, aged about 40 years.

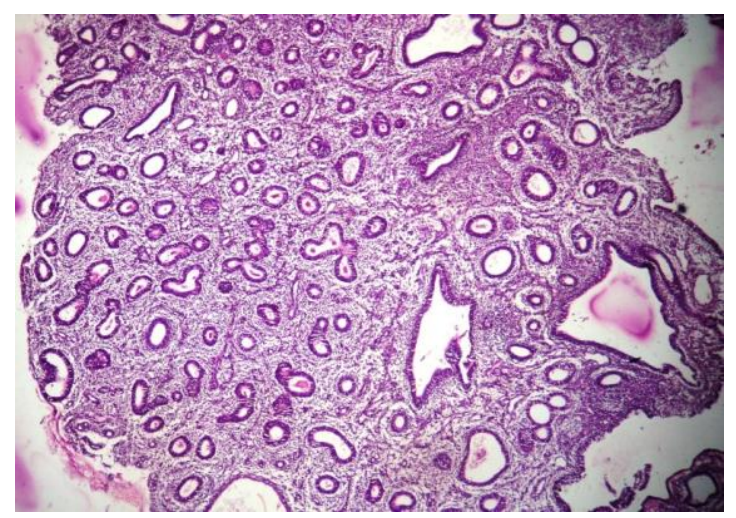

Fig. 3. Microphotograph of simple hyperplasia phase showing glands of varying sizes and shapes with cystic dilatation and increased gland to stroma ratio

The age distribution pattern in various organic lesions shows that almost all the lesions occurred between the age group of 31-40 years, accounting for maximum number of cases of $46.29 \%$. The maximum number of adenomyosis (AD) and leiomyomas occurred in the age group between 31-40 yrs and 41-50 years respectively. Endometrial polyp (EP) was encountered in age group of 31-40 years in 3 cases. Products of conception (DegP) was found in one case.

Our study showed maximum number cases of AUB had low haemoglobin between $8-10 \mathrm{gm} \%$ accounting for $52.25 \%$ of the cases.

Adenomyosis was the commonest organic pathology encountered accounting for 23 cases $(40.36 \%)$ followed by leiomyomas in 20 cases
(35.09\%). Adenomyosis with leiomyomas were reported in 4 cases $(7.02 \%)$, endometrial polyp in 2 $(3.51 \%)$ cases and degenerated products of conception in one $(1.75 \%)$ case. Endometrial polyp associated with adenomyosis and leiomyomas in $3(5.26 \%)$ cases and 1 case respectively. Decidual reaction associated with adenomyosis and leiomyomas in $2(3.51 \%)$ cases and 1 case respectively.

In the associated myometrial lesions also, proliferative phase $(43.01 \%)$ was the most common endometrial pattern followed by endometrial hyperplasia accounting for $20.69 \%$ of cases, associated especially with leiomyomas. Secretory phase and atrophic endometrium were observed in $13.79 \%$ and $6.90 \%$ of cases respectively.

In the present study, $15(13.5 \%)$ cases showed incidental lesions other than those involving the body of uterus. Follicular cyst was reported in 10 cases. Three cases of serious cystadenoma were encountered along with two cases of cervical leiomyoma.

\section{Discussion}

Normal menstruation is defined as the bleeding from secretary endometrium associated with an ovulatory cycle with not more than five days in length. Any bleeding not fulfilling these criteria is referred to as abnormal uterine bleeding (AUB). ${ }^{9}$

As AUB is common gynaecological disorder in perimenopausal women it needs through evaluation of the patient as it the only alarming symptom and needs through evaluation as this is the only clinical manifestation of endometrial carcinoma. ${ }^{10}$

In clinicopathological study of 100 hysterectomies by Shergill et al., ${ }^{11}$ the main indications for hysterectomy were leiomyoma (34\%), DUB (26\%) and uterine prolapse $(24 \%)$. In united states (Kramer \& Reiter), hysterectomy is frequently performed for uterine fibroids, DUB, endometriosis / adenomyosis, chronic pelvic pain and genital prolapsed. ${ }^{12}$ However, an incidence of $49.65 \%$ was obtained in an analysis of 719 cases of hysterectomies by Patel et al. of which 357 were performed for DUB. ${ }^{13}$ Thus, the incidence is seen to variable probably depending on the geographical regions. Whereas present study reported $17.84 \%$ of the total hysterectomies.

In the present study, both the reproductive and the perimenopausal age groups were involved $\left(4^{\text {th }} \& 5^{\text {th }}\right.$ decades, $82.08 \%)$. Our results are in concordance with Pilli et al. $(96 \%),{ }^{8}$ Patel et al. $(89 \%)^{13}$ and Ghosh \& Sengupta $(76 \%)^{14}$ reported most cases in $4^{\text {th }} \& 5^{\text {th }}$ decades. Purandhare \& Jhalam reported more that $65 \%$ of the patients belonged to the age group of 40-50 years. ${ }^{7}$ In contrast, the review of 150 cases by Mehrotra et al. ${ }^{15}$ found maximum incidence in the age group of 21-30 years. While Dass and Chugh and Bhattacharji reported higher incidence in 31-40yrs of age. ${ }^{16,17}$

In our study, the comparison of symptoms reveals a similar pattern in various studies ${ }^{8,13,18}$ Pilli et al. $(34 \%),{ }^{5}$ 
Mehrotra et al. $(52 \%)^{15} \&$ Sagar S $(40.9 \%)^{18}$ found higher incidence of menorrhagia followed by metrorrhagia. The incidence of metrorrhagia reported by Sagar S (15.8\%) \& Mehrotra et al. (19.3\%) is comparable with the present study $(13.51 \%) .{ }^{15,18}$

Joshi \& Deshpande ${ }^{19}$ observed maximum duration of symptoms was between 1-6 months (37\%) and $27.6 \%$ of patients had symptoms for more than one year. Similar observations were made in the present study. Ghosh \& Sengupta ${ }^{14}$ reported highest percentage of patients $(82 \%)$ had symptoms for more than one year. The difference probably is due to the disparity in the educational status of the patients and the severity of the symptoms produced.

Majority of the cases in the present study were multiparous $(93.69 \%)$, similar observations were made by Joshi \& Deshpande $(61.5 \%),{ }^{19}$ Rosario $(97 \%)^{20}$ and Pilli et al. $(87 \%)^{8}$ reported highest incidence in multiparous women. It is also observed that the general population shows a higher incidence of multiparity.

Table 4: The comparison of endometrial patterns of AUB in various studies.

\begin{tabular}{|l|c|c|c|c|}
\hline $\begin{array}{c}\text { Lesions/ endometrial } \\
\text { pattern }\end{array}$ & $\begin{array}{c}\text { Purandhare\& } \\
\text { Jhalam L (\%) }\end{array}$ & $\begin{array}{c}\text { Lotha L et } \\
\text { al (\%) }\end{array}$ & $\begin{array}{c}\text { Usha GD et } \\
\text { al. (\%) }\end{array}$ & $\begin{array}{c}\text { Present study } \\
(\%)\end{array}$ \\
\hline Proliferative Phase & 66.3 & 41.4 & 44.7 & 49.54 \\
\hline Secretory Phase & 20.6 & 5.4 & 23.5 & 15.31 \\
\hline Atrophic Phase & 6.1 & 2.0 & 5.8 & 5.40 \\
\hline Simple hyperplasia & 7.0 & 48.6 & 9.4 & 15.31 \\
\hline Complex hyperplasia & - & - & - & 9.01 \\
\hline $\begin{array}{l}\text { Complex hyperplasia with } \\
\text { atypia }\end{array}$ & - & & - & 0.90 \\
\hline Endometrial polyp & - & - & - & 5.40 \\
\hline Decidual reaction & - & - & - & 2.70 \\
\hline Others & - & - & - & - \\
\hline
\end{tabular}

The most common endometrial pattern obtained in various studies is proliferative phase, the percentage varying from $34 \%$ to a maximum of $66 \%$. This reflects the nature of abnormality in AUB being that of anovulation or unopposed oestrogen action. ${ }^{7}, 8,13$ Proliferative phase of the present study correlates well with Purandhare \& Jhalam $(66.3 \%)^{7}$ and Usha et al. $(44.7 \%)^{21}$ studies. The incidence of endometrial hyperplasia was found to be the maximum $(48.6 \%)$ in Lotha et al. study ${ }^{22}$ which partly reflects hyperoestrogenic activity. Ghosh \& Sengupta (70\%), ${ }^{16}$ and Rosario $(33.55 \%)^{20}$ reported highest incidence of endometrial hyperplasia. While present study reported endometrial hyperplasia in $25.22 \%$ of cases.

Menorrhagia is one of the commonest causes of iron deficiency anaemia in women of the reproductive age group. $^{9}$ A comparison of the haemoglobin percentage shows a similar pattern of prevalence of varying degrees of anaemia in AUB patients. The development of iron deficiency anaemia initiates a compensatory mechanism which tends to reduce blood loss. ${ }^{17}$ In the present study, microcytic hypochromic anaemia was found in $16.8 \%$ of cases.

The incidence of DUB cases without organic lesions encountered in this study were as high as $51.35 \%$. Similar observations were made by, Dass \& Chugh $(63.4 \%),{ }^{16}$ Purandhare and Jhalam $(63 \%)^{7}$ and Pilli et al. $(85 \%)^{8}$ reported higher incidence of DUB without organic lesions. Whereas Shergill et al. $(66.6 \%)^{11}$ and Ghosh \& Sengupta $(66 \%)^{14}$ reported Thigher incidence of intrauterine organic lesions comparable to the incidence of $48.65 \%$ in the present study.

The endometrial pattern in DUB cases without organic pathology reveals a predominance of proliferative phase in most of the studies, suggesting that anovulation to be the main cause of DUB. ${ }^{7,13,16}$ The incidence of proliferative phase in present study $(50.88 \%)$ is comparable with Dass \& Chugh $(41.5 \%)^{16}$ and Mehrotra et al. (62.5\%). ${ }^{15}$ While Bhattacharji $(19.6 \%)^{17}$ and Joshi \& Deshpande $(31.7 \%)^{19}$ reported lower incidence of proliferative phase. The incidence of endometrial hyperplasia varies in different studies from $7 \%$ to $31.4 \% .^{16,17,19}$ However, the percentage of endometrial hyperplasia obtained in this study is $29.83 \%$ is in accordance with Patel et al. $(29.1 \%)^{13}$ and Dass \& Chugh $(30.6 \%)^{16}$ studies and lowest in the study of Purandhare \& Jhalam (7\%). ${ }^{7}$

Similarly, the percentage incidence of secretary phase varied from $5.3 \%$ to $43.9 \% .^{7,13,15,16}$ The incidence of secretary phase $(15.79 \%)$ in present study is comparable with Joshi and Deshpande (16.7\%). ${ }^{19}$ The highest incidence of secretary phase was reported by Bhattacharji $(43.9 \%)^{17}$ and lowest incidence of $5.3 \%$ in Mehrotra et al. ${ }^{15}$ studies. The discrepancy may be due to the fact that unlike D\&C, which is performed in the premenstrual phase, performing hysterectomy is not bound by the phase of menstrual cycle. The percentage of atrophic endometrium (3.50\%) in the present study is in concordance with the study of Dass \& Chugh $(1.8 \%) .{ }^{16}$ Bhattacharji reported higher incidence of $7.3 \% .{ }^{17}$ 
There were 54 cases in the present study which showed organic lesions. Endometrial patterns with various organic lesions shows a predominance of proliferative phase $(43.10 \%)$ in majority of lesions. ${ }^{7,8.13,23}$

Sanyal et al. ${ }^{23}$ reported higher incidence of normal endometrium (proliferative \& secretary, 82\%), hyperplastic in $7 \%$ and atrophic in $4 \%$ and the results are in accordance with the present study.

Majority of the lesions were constituted by adenomyosis $(40.36 \%)$ followed by leiomyomas (35.09\%). Similar results were observed by Purandhare and Jhalam $(52.5 \%),{ }^{7}$ Pilli et al. $(40 \%)^{8}$ and Ghosh \& Sengupta (46\%). ${ }^{14}$ Rosario $^{20}$ reported higher incidence of adenomyosis in $77.7 \%$ of cases.

Whereas other studies have reported higher incidence of leiomyomas in Shergill et al. $(66.3 \%),{ }^{11}$ Dass \& Chugh $(45.5 \%)^{16}$ \& Sanyal et al. $(60.8 \%){ }^{23}$

However, Dass \& Chugh observed leiomyomas in majority of the cases were only seedling fibroids and adenomyosis was not a marked feature. Therefore, these lesions would have probably remained undiagnosed if detailed histopathological study had not been undertaken. ${ }^{16}$

Endometrial lesions shows a predominance of proliferative phase in the present study. Similarly, Purandhare and $\mathrm{Jhalam}^{7}$ and Sanyal et al. ${ }^{23}$ series reported proliferative phase as the dominant type of endometrium in cases associated with adenomyosis and leiomyomas. In comparison with the retrospective study of cases associated with adenomyosis with leiomyomas by Purandhare and Jhalam ${ }^{7}$ with the present study, the percentage incidence of proliferative phase was slightly lower and that of cystoglandular hyperplasia slightly higher. The probable cause may be the fact that the hyperestrogenic state responsible for the hyperplastic lesions may be the causative factor of the organic lesions as well. The atrophic endometrium associated with leiomyomas was probably due to the mechanical and hormonal factors. ${ }^{23}$

There were other extra - corporal incidental lesions other than those involving the body of uterus in $13.5 \%$ of the cases. A review of 137 cases of premenopausal women by

Rosario $^{20}$ found the occurrence of follicular cysts in $39(28.46 \%)$ cases, four cases were associated with hydrosalphinx and two cases with simple ovarian cysts. While follicular cyst in the present study was reported in $9.34 \%$ of cases and hydrosalphinx in one case. A study of 274 cases of DUB by Joshi and Deshpande, found ovarian cysts, cervical polyps and cervical erosions in $12.7 \%, 7.5 \%$ and $6.3 \%$ of the cases, respectively. ${ }^{19}$

\section{Conclusion}

Abnormal uterine bleeding as become one of the commonest problem among women. Evaluation of such patients is important in diagnosing various histological patterns and etiopathological factors. Hence histopathological evaluation is mandatory in diagnosing the cases of abnormal uterine bleeding cases.

Besides this, it is observed that the age of the patient had a strong bearing on the type and pattern of endometrium seen on histopathological examination. Hence age plays an important role in diagnoses of endometrial pathology.

Histopathological examination of endometrium remains the gold standard method of evaluating the DUB cases and its subtypes and to exclude the local causes which helps in early diagnosis and to determine the plan and mode of management.

\section{Reference}

1. Crum C.P. The Female Genital tract. In: Kumar V, Abbas, Fausto N. Editors. Robbins and Cotran Pathologic Basis of Disease. $7^{\text {th }}$ ed. New Delhi, India: Saunders. 2004;1079-90.

2. Pyari J. S, Rekha S, Srivastava P.K, Goel M, Pandey M. J. Obstet Gynecol India. 2006;56(3):240-243.

3. ACOG Practice Bulletin: Clinical Management of Anovulatory Bleeding. Int J Gynaecol Obstet 2001;72(3):263-71.

4. Iram S, Musonda P, Ewies AAA. European Journal of Obstetrics \& Gynecology and Reproductive Biology. 2010;148:86-89.

5. Mutter GL: Diagnosis of premalignant endometrial disease. J Clin Pathol, 2002;55:326-331.

6. Hacker N.F, Moore J.G, editors. Dysfunctional Uterine Bleeding. In: Essentials of Obstetrics and Gynecology. $3^{\text {rd }}$ ed. Singapore: Harcourt Brace \& Company. Asia PTE Ltd. 1998. pp. 441-445.

7. Purandare S, Jhalam L. Pathological picture in Hysterectomy done for abnormal uterine bleeding. $J$ Obstet Gynaecol India. 1993;43:418-21.

8. Pilli G.S, Sethi B, Dhaded A.V, Mathur P.R. Dysfunctional Uterine Bleeding. (Study of 100 cases). $J$ Obstet Gynaecol India 2002;52(3):87-89.

9. Kramer M.G, Reit Rosai J. Female reproductive system Uterus - corpus. In: Rosai J Ed. Rosai and ackerman's surgical pathology $9^{\text {th }}$ ed. Vol 2, Missouri;Mosby. 2004. pp.1569-1635.

10. Sloboda L, Molnar E, Popovic Z, Zivkovic S. Analysis of pathohistological results from the uterine mucosa 196598 at the gynecology department in Senta. Med Pregl 1999;52(6- 78$): 263-65$.

11. Shergill S,K, Shergill H.K, Gupta M, Kaur S. Clinicopathological Study of Hysterectomies. JIMA. 2002;100(4):238-9,246.

12. er R.C. Hystrectomy: indications, alternatives and predictors. Am Fam Physician. 1997;55(3):827-34.

13. Patel S.R, Sheth M.S, Rawal M.Y. Dysfunctional Uterine Bleeding-Place of Hysterectomy in its Management. $J$ Postgrad. 1986;32(3):150-3.

14. Ghosh B.K, Sengupta K.P. A study of the endometrium and cystohormonal pattern in functional uterine bleeding. J Obstet Gynaeol India.1968;310-6.

15. Mehrotra V.G, Mukerjee K, Pandey M, Samanth V. Functional uterine bleeding (A review of 150 cases.) $J$ Obstet Gynaecol India. 1972;22:684-9.

16. Dass A. Chugh S. Dysfunctional Uterine Bleeding: A clinic- pathological study. J Obstet Gynaecol India. $1964 ; 14: 348-54$. 
17. Bhattacharji S.K. Dysfunctional uterine hemorrhage: correlation of endometrial pattern with clinical behaviour. J Obstet Gynaecol India. 1964;14:372-9.

18. Sagar S. Clinico-pathological correlation of abnormal uterine bleeding in patients at the age of 45 years and above. J Obstet Gynaecol India. 1980;30:165-69.

19. Joshi S.K, Deshapande D.H. Clinico- pathological study in 274 cases of dysfunctional uterine hemorrhage. $J$ Obstet Gynaecol India.1964;14:360-71.

20. Rosario Y.P. Dysfunctional uterine bleeding in the premenopausal age (A review of 137 cases). J Obstet Gynaecol India. 1969;19:606-14.

21. Usha GD, G.B. Dodamani, Geetanjali K, Ashalatha M. Clinicopathological correlation of endometrium in abnormal uterine bleeding. Sch. J. app. Med. Sci. 2014;2(1A):46-49.
22. Lotha L, Asha B. Clinicopathological evaluation of abnormal uterine bleeding in perimanopausal women. Int. J. Reprod Contracept Obstet Gynecol.2016;5(9):30723074.

23. Sanyal M.K, Sanyl S, Bhattacherjee K.K, Roy Choudhari N.N. Clinico- pathological study of endometrium: A review of three thousand nine hundred twenty cases in different gynaecological abnormalities. J Obstet Gynaecol India. 1981;31(5):816-21.

How to cite this article: Ramesh $\mathrm{BH}$, Rajeshwari K. Clinico-histomorphological spectrum of abnormal uterine bleeding. Ind $\mathbf{J}$ Pathol Oncol, 2018;5(3):477-483. 